\title{
The Effects of Stabilization Exercises and Cognitive Behavioral Therapy in People with Chronic Low Back Pain
}

\author{
Gozdelyigun*, Ender Angin and Berkiye and Kirmizigil \\ Eastern Mediterranean University, Turkey \\ *Corresponding author: Gozdelyigun, Eastern Mediterranean University, Turkey
}

Submission: 浅 August 15, 2018; Published: 阱 August 17, 2018

\section{Opinion}

The lifetime prevalence of non-specific chronic low back pain (LBP) is estimated at $60-70 \%$ in industrialized countries which is a common health problem worldwide. Approximately 5-15\% of LBP cases can be attributed to a specific cause (i.e. osteoporotic fracture, neoplasm or infection) while for the remaining $85-95 \%$ the specific cause of LBP is unclear [1,2]. LBP is the leading cause of activity limitation and work absence throughout much of the world, imposing a high economic burden on individuals, families, communities, industry, and governments $[3,4]$. It is know that $80 \%$ of patients with acute LBP are recovering within 6 weeks, while $7-10 \%$ of the patients with LBP become chronic (longer than 7-12 weeks) which has a very poor prognosis with recovery leading to work absence and economic loss [5]. Chronic LBP is a neurophysiological disorder affected by multiple factors (such as individual characteristics, working conditions like heavy physical work, bad working postures, lifestyle factors and psychological factors) which may lead to fear of pain causing activity limitations and decrease in participation. Due to prolonged period of pain caused by LBP patients may gradually decrease their occupational work-related activities and other physical activities [6].

Weakening of the superficial trunk and abdominal muscles and insufficient motor control of the deep trunk muscles, such as the lumbar multifidus and transversus abdominis are amongst the physical consequences of LBP. Lack of awareness of back health and decreased physical activity level leads to muscle weakness of the "core" which has been described as a central column with the abdominals in front, paraspinals and gluteal in the back, the diaphragm as the roof, and the pelvic floor and hip girdle musculature as the bottom which provides stability to the spinal column [7]. Lumbar multifidus muscle has a very important role in maintaining the spinal stability. Regaining the strength and endurance of lumbar multifidus muscle is considered essential for restoring the proper function of the "core". Therefore, recruiting and strengthening the lumbar multifidus muscle is very important part of rehabilitation to improve functions in patients with LBP. It is stated that the spinal mobility is as important as spinal stability. Movements of the spine is necessary to disperse forces and minimize energy expenditure. The rigidity of the spine increases the energy consumption and loading of the spinal segments. There are still questions in the literature for the clinical significance of spinal stabilization $[8,9]$. There is evidence of loss of function in deep muscles that provides stabilization in patients with LBP. In addition, it has been reported that latissimus dorsi, superficial paraspinal and abdominal muscles supports the lumbar stabilization, especially in weight bearing. It is suggested that these muscles should be included in lumbar stabilization programs. It has been shown that people with chronic LBP have weakness of "core" muscles and that the motor control of these muscles are impaired. In systematic reviews is stated that stabilization and strengthening programs are useful in the treatment of LBP $[10,11]$. Improving athletic performance, relieving back pain and preventing injuries are amongst the benefits of core stabilization. A stabilization exercise, especially by increasing the activation of the atrophied multifidus muscle, increase the lumbar stabilization and increases the muscular support against the possible stresses [12]. There is insufficient evidence for the appropriate exercise programs for core muscle strengthening in individuals with chronic LBP [13]. The start of this modern era in chronic pain treatment began with the publication of the gate control theory of pain, emphasizing the importance of cognitive and affective, as well as sensory, influences on pain. Pain is influenced by biological, psychological, and social factors and optimally managed by treatments focusing on psychological and social influences besides its biological causes [14]. It is indicated that back pain circuits shift from the nociceptive center to the emotional center within 12 months of onset [15]. It is known thatpatients with chronic pain experience anger. Undiminished anger, on the other hand may create a hypervigilant state of arousal and magnifyies the pain [16]. Central sensitization is the response by reducing the inhibition of the inflammatory or injured somatosensory nervous system and increasing the excitability of nociceptive nerve fibers. Central sensitization spatially and perceptually reduces the pain 
threshold of a person and leads to hypersensitivity [17]. Pain pathways, mental and physical, are structurally imbedded and it takes neuroplastic reorganization to recover from chronic pain [18]. It is indicated that chronic pain reduces both gray and white matter volume in pain processing regions and the pain brain map grows and the motor cortex map shrinks. Fortunately, these maps can be reversed with treatment [19].

Cognitive behavioral therapy (CBT) was found to increase grey matter volume in the brain [20]. In the literature, CBT in spinal pathologies (cervical-lumbar) has been found to have important effects on reducing pain and disability and improving function [2123]. The CBT aims to reduce the pain and psychological distress in order to improve physical and role functions by decreasing maladaptive behaviors, increasing adaptive behaviors, identifying and correcting maladaptive thoughts and beliefs, and increasing self-efficacy for pain management [24]. CBT plays an important role in patients' self-definition, learning to cope with pain and consequences. The disease provides physical and psychosocial recovery to reduce pain in specific activities (gradual increase, sequencing, actual treatment, etc.) with cognitive (cognitive restructuring, cognitive restructuring, imagination and relaxation techniques etc.) and behavioral modifications [25-27].

There is need for further research to answer the questions about 'which therapy approaches (e.g. spinal stabilization exercises, CBT) are more effective for the treatment of LBP?', 'does it work better if we include the patients in the treatment program?' or 'which patients benefits more from the treatment?'. Patients with LBP would also be a partner in a shared decision-making process with clinicians and they must have higher internal locus of control(individual believes that he/she is responsible for his/her own health). It is an indisputable fact that increased knowledge of patients about the LBP and guiding them within the therapy will increase the efficacy of the treatment. Researches should be done for identifying the place of the patients in the treatment which might be more cost-effective approach for the treatment of LBP and to reduce the economic burden of the health care systems and governments.

\section{References}

1. Duthey B (2013) Priority medicines for europe and the world: "a public health approach to innovation". Background Paper 6.24 Low back pain.

2. Andersson GB (1999) Epidemiological features of chronic low-back pain. Lancet 354(9178): 581-585.

3. Taimela S, Kujala UM, Salminen JJ, Viljanen T (1997) The prevalence of low back pain among children and adolescents: a nationwide, cohortbased questionnaire survey in Finland. Spine 22(10): 1132-1136.

4. Andersson GBJ (1997) The epidemiology of spinal disorders. In: Frymoyer JW (Ed.), The adult spine: principles and practice. Philadelphia, USA, pp. 93-141.

5. Tulder VMW, Koes BW, Bouter LM (1997) Conservative treatment of acute and chronic nonspecific low back pain. A systematic review of randomized controlled trials of the most common interventions. Spine 22(18): 2128-2156.
6. Jemmett RS (2003) Rehabilitation of lumbar multifidus dysfunction in low back pain: strengthening versus a motor re-education model. Br J Sports Med 37(1): 91-94.

7. Richardson C, Jull G, Hodges P, Hides J (1999) Therapeutic exercise for Spinal Segmental Stabilization in Low Back Pain: Scientific Basis and Clinical Approach. Churchill Livingstone. Edinburgh, New York, USA.

8. McGill S (2002) Low back disorders: evidence-based prevention and rehabilitation. ( $1^{\text {st }}$ edn), Champaign Human Kinetics, Illinois, USA, pp. 239-257.

9. Kuukkanen TM, Malkia EA (2000) An experimental controlled study on postural sway and therapeutic exercise in subjects with low back pain. Clin Rehabil 14(2): 192-202.

10. Hodges PW, Richardson CA (1998) Delayed postural contraction of transversus abdominis in low back pain associated with movement of the lower limb. J Spinal Disord 11(1): 46-56.

11. May S, Johnson R (2008) Stabilisation exercises for low back pain: a systematic review. Physiotherapy 94: 179-189.

12. Hides JA, Stanton WR, McMahon S (2008) Effect of stabilization training on multifidus muscle cross-sectional area among young elite cricketers with low back pain. J Orthop Sports Phys Ther 38(3): 101-108.

13. Arokosk JP, Valta T, Kankaanpaa M, Airaksinen O (2004) Activation of lumbar paraspinal and abdominal muscles during therapeutic exercises in chronic low back pain patients. Arch Phys Med Rehabil 85(5): 823832 .

14. Ehde DM, Dillworth TM, Turner JA (2014) Cognitive-behavioral therapy for individuals with chronic pain: efficacy, innovations, and directions for research. The American psychologist 69(2): 153-166.

15. Hashmi JA, Baliki MN, Huang L (2013) Shape shifting pain: chronification of back pain shifts brain representation from nociceptive to emotional circuits. Brain 136(Pt 9): 2751-2768.

16. Abbass A, Lovas D, Purdy A (2008) Direct diagnosis and management of emotional factors in chronic headache patients. Cephalalgia 28(12): 1305-1314.

17. Latremoliere A, Woolf C (2009) Central sensitization: a generator of pain hypersensitivity by central neural plasticity. The Journal of Pain 10(9): 895-926.

18. Woolf CJ (2011) Central sensitization: implications for the diagnosis and treatment of pain. Pain 152(3 Suppl): S2-S15.

19. Seminowicz DA, Wideman TH, Naso L (2011) Effective treatment of chronic low back pain in humans reverses abnormal brain anatomy and function. J Neurosci 31(20): 7540-7550.

20. Seminowicz DA, Shpaner ML, Krauthamer GM, Newhouse PA, Filippi CG, et al. (2013) Cognitive-behavioral therapy increases prefrontal cortex gray matter in patients with chronic pain. J Pain 14(12): 1573-1584.

21. Richmond H, Hall AM, Copsey B, Hansen Z, Williamson E, et al. (2015) The effectiveness of cognitive behavioural treatment for non-specific low back pain: a systematic review and meta-analysis. PLoS One 10(8): e0134192.

22. Hay EM, Mullis R, Lewis M, Vohora K, Main CJ, et al. (2005) Comparison of physical treatments versus a brief pain-management programme for back pain in primary care: a randomised clinical trial in physiotherapy practice. Lancet 365(9476): 2024-2030.

23. Fersum KV, O’Sullivan P, Skouen JS, Smith A, Kvåle A (2013) Efficacy of classification-based cognitive functional therapy in patients with nonspecific chronic low back pain: A randomized controlled trial. Eur J Pain 17(6): 916-928. 
24. Turner JA, Romano JM (2001) Cognitive-behavioral therapy forchronic pain. In: Loeser JD, Bonica JJ (Eds.), Bonica's management of pain $\left(3^{\text {rd }}\right.$ edn.), Lippincott Williams \& Wilkins, Philadelphia, USA, pp. 1751-1758.

25. Smeets RJEM, Vlaeyen JWS, Kester ADM, Knottnerus JA (2006) Reduction of pain catastrophizing mediates the outcome of both physical and cognitive-behavioral treatment in chronic low back pain. Journal of Pain 7(4): 261-271.
26. Reid MC, Otis J, Barry LC, Kerns RD (2003) Cognitive-behavioral therapy for chronic low back pain in older persons: a preliminary study. Pain Medicine 4(3): 223-230.

27. Monticone M, Cedraschi C, Ambrosini E, Rocca B, Fiorentini R, et al. (2015) Cognitive-behavioural treatment for subacute and chronic neck pain. Cochrane Database Syst Rev 26(5): CD010664.

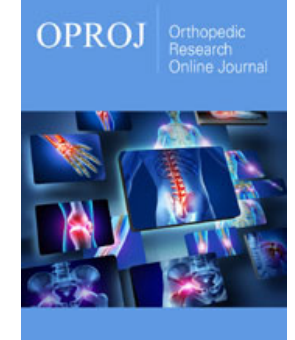

\section{Orthopedic Research Online Journal}

\section{Benefits of Publishing with us}

- High-level peer review and editorial services

- Freely accessible online immediately upon publication

- Authors retain the copyright to their work

- Licensing it under a Creative Commons license

- Visibility through different online platforms 